\title{
Elevated Serum Triglycerides are Associated with Ketosis-Prone Type 2 Diabetes in Young Individuals
}

This article was published in the following Dove Press journal: Diabetes, Metabolic Syndrome and Obesity: Targets and Therapy

\author{
Shu Ye ${ }^{1, *}$ \\ Hui Ran',* \\ Hongmei Zhang' \\ $\mathrm{Hui} \mathrm{Wu}^{2}$ \\ Wen $\mathrm{Li}^{1}$ \\ Shichun Du' \\ Qing Su'
}

'Department of Endocrinology, Xin Hua Hospital Affiliated to Shanghai Jiao Tong University School of Medicine, Shanghai 200092, People's Republic of China;

${ }^{2}$ Department of Endocrinology, Zhejiang Provincial People's Hospital, Hangzhou Medical College, Hangzhou, 310014 ,

People's Republic of China

*These authors contributed equally to this work
Correspondence: Shichun Du Department of Endocrinology, Xin Hua Hospital Affiliated to Shanghai Jiao Tong University School of Medicine, Kong Jiang Road I665\#, Shanghai, 200092, People's Republic of China

Email dushichun@xinhuamed.com.cn
Purpose: Ketosis-prone type 2 diabetes (KPT2D) is increasingly recognized in young adults. However, the role of blood lipids in KPT2D, especially serum triglycerides (TGs), is not yet clearly understood.

Patients and Methods: We retrospectively evaluated 409 young patients diagnosed with KPT2D or classical type 2 diabetes (T2D) attending an academic tertiary hospital. Clinical characteristics and laboratory findings were compared between KPT2D and T2D patients. ANOVA or a non-parametric test analyses were used to evaluate differences in clinical characteristics and laboratory findings. Multivariate regression analyses and stratified analyses were used to further investigate differences in serum TGs levels between KPT2D and T2D individuals.

Results: KPT2D is a subtype of T2D with traits of overweight or obesity. However, hyperglycemia and impaired $\beta$-cell functions were more severe in KPT2D patients. Serum TGs levels were significantly higher $(P=0.0003)$ in KPT2D individuals. Furthermore, the proportion of very high serum TGs levels was 6 -fold higher $(P<0.0001)$ in KPT2D than in T2D patients. Elevated serum TGs were associated with young KPT2D patients.

Conclusion: Lifestyle changes as well as lipid-lowering treatments might be effective in lowering the incidence of ketosis as well as stabilizing disease progression.

Keywords: ketosis, triglycerides, hypertriglyceridemia

\section{Introduction}

Diabetic ketosis or ketoacidosis is a severe complication of diabetes usually observed in individuals with type 1 diabetes (T1D) and is caused by a deficiency of endogenous insulin. However, Winter et al first reported that the prevalence of ketosis or ketoacidosis was becoming increasingly common in an atypical form of type 2 diabetes (T2D) in $1987 .{ }^{1}$ Recently, youth-onset ketosisprone type 2 diabetes (KPT2D) has attracted increasing attention. ${ }^{2}$ Zhang et al have reported $7.6 \%$ prevalence of KPT2D in young diabetic patients in $\mathrm{China}^{3}$ and Nagasaka et al reported approximately $10 \%$ in Japan. ${ }^{4}$ KPT2D has been shown to have better retention of $\beta$-cell functions compared to T1D, but exhibits stronger insulin resistance and temporarily suppressed $\beta$-cell functions compared to the classical T2D in our ${ }^{5}$ and other previous studies. ${ }^{6,7}$ Similar to patients with T2D, those with KPT2D are also likely to be overweight and have a strong family history of diabetes. ${ }^{5-7}$ Therefore, KPT2D has also been called the Flatbush, idiopathic, or type 1.5 diabetes. It has been reported that glucotoxicity 
characterized by high levels of glycosylated hemoglobin $\mathrm{A} 1 \mathrm{c}(\mathrm{HbA} 1 \mathrm{c})$ can suppress $\beta$-cell functions, resulting in ketosis or ketoacidosis in individuals with KPT2D. ${ }^{7}$ However, few previous studies have systematically studied serum triglycerides (TGs) levels in patients with KPT2D. Several studies have also suggested higher serum triglycerides in ketosis-prone diabetes. ${ }^{3,8}$ However, most of the study samples were relatively small and the distributions of serum TGs were not investigated. To better understand lipid metabolism in KPT2D, we explored the similarities as well as differences in clinical characteristics between patients with T2D and KPT2D, especially with regard to serum TGs. We speculated that elevated serum TGs might be an important clinical characteristic of young individuals with KPT2D, and therefore, this study might provide new insights and potential approaches to treat KPT2D.

\section{Patients and Methods Subjects}

This retrospective study was conducted at the Endocrinology Department of Xin Hua Hospital affiliated with Shanghai Jiao Tong University School of Medicine. The study protocol was approved by the Ethics Committee of the Xin Hua Hospital and a waiver of individual consent was approved due to the retrospective nature of the study. This study was conducted in accordance with the Declaration of Helsinki. Patient data confidentiality was maintained. All the enrolled patients with new-onset diabetes were between the ages of 12 and 40 years and were hospitalized for medical treatment from Jan 2009 to Oct 2020. A total of 409 cases (213 KPT2D and 196 T2D) were included in the analysis after excluding 56 cases. The exclusion criteria for this study were consistent with our previous report. ${ }^{5}$ Cases with T1D were excluded due to dependence on insulin treatment, positivity for $\beta$ cell autoantibodies, and undetectable/low levels of plasma C-peptide. The diagnosis of T2D was based on the America Diabetes Association Guidelines of 2006, with fasting plasma C-peptide $>0.33 \mathrm{nmol} / \mathrm{L}^{9}$ and without ketosis or ketoacidosis. The diagnostic criteria of KPT2D were described previously. ${ }^{5}$ Briefly, KPT2D patients were new-onset T2D patients with unprovoked ketosis or diabetic ketoacidosis as the primary symptom. ${ }^{5}$ All enrolled patients (both KPT2D and T2D) were negative for islet cell autoantibodies (ICAs), glutamate decarboxylase autoantibodies (GADs), and insulin autoantibodies (IAAs).
The anthropometric measurements and clinical data collections were consistent with previous research. ${ }^{5}$

\section{Classification According to Serum Triglyceride Levels}

Based on the National Cholesterol Education Program Adult Treatment Panel III criteria ${ }^{10}$ for serum TG levels, patients were classified into four groups: normal (TGs $<$ $1.7 \mathrm{mmol} / \mathrm{L}$ ), borderline-high (TGs $\geq 1.7 \mathrm{mmol} / \mathrm{L}$ and $<$ $2.3 \mathrm{mmol} / \mathrm{L}$ ), high (TGs $\geq 2.3 \mathrm{mmol} / \mathrm{L}$ and $<5.6 \mathrm{mmol} / \mathrm{L}$ ), and very high (TGs $\geq 5.6 \mathrm{mmol} / \mathrm{L})$ groups.

\section{Statistical Analysis}

Data were analyzed using JMP 9.0 (SAS Institute). A twotailed $P$-value $<0.05$ was considered statistically significant. Normally distributed continuous variables are presented as mean \pm SEM. Skewed variables have been presented as median (interquartile range, IQR). The results of comparisons of data between the two groups were analyzed by ANOVA or a non-parametric test. Pearson's correlation coefficients were calculated to investigate the relationship between serum TGs and other variables. Multivariate regression analysis was used to assess differences in serum TGs by adjusting variables. Stratified analyses were used to investigate different levels of serum TGs. The non-normal distributions of continuous variables including serum TGs and C-peptides were log-transformed for the analyses.

\section{Results}

\section{The Characteristics and Anthropometric Features of Subjects}

The characteristics of the KPT2D and T2D groups are shown in Table 1. The individuals in the KPT2D group were significantly younger at presentation $(29 \pm 0.5$ years $)$ than those in the T2D $(33 \pm 0.5$ years $)$ group $(P<0.0001)$. The KPT2D group had a higher proportion of males $(87 \%)$ than the traditional T2D (73\%) group $(P=0.0004)$. Most patients with new-onset KPT2D presented symptoms abruptly, with an average of $2.5 \pm 0.3$ months of polyuria, polydipsia, and weight loss. The body mass index (BMI) was similar in KPT2D $\left(28.9 \pm 0.3 \mathrm{~kg} / \mathrm{m}^{2}\right)$ and T2D groups $\left(28.0 \pm 0.3 \mathrm{~kg} / \mathrm{m}^{2}, P=\mathrm{NS}\right)$. Up to $60 \%$ of patients with KPT2D had a family history of T2D.

\section{Laboratory Findings of Subjects}

The laboratory results are shown in Table 2. The KPT2D group had higher levels of fasting plasma glucose (FPG) $(P<$ 
Table I Anthropometric and Clinical Features of KPT2D and T2D Subjects

\begin{tabular}{|c|c|c|c|c|}
\hline & KPT2D & T2D & $\mathbf{P}$ & P Adjusted \\
\hline Subjects (n) & 213 & 196 & - & - \\
\hline Age (yr) & $29 \pm 0.5$ & $33 \pm 0.5$ & $<0.0001$ & - \\
\hline Gender (male \%) & 87 & 73 & 0.0004 & - \\
\hline Duration (months) & $2.5 \pm 0.3$ & $8.1 \pm 0.6$ & $<0.0001$ & $<0.0001$ \\
\hline Diabetic family history (\%) & 60 & 58 & 0.76 & 0.25 \\
\hline Height $(\mathrm{cm})$ & $174 \pm 0.6$ & $|7| \pm 0.6$ & 0.0006 & 0.37 \\
\hline Weight (kg) & $88 \pm 1.1$ & $82 \pm 1.1$ & 0.0002 & 0.02 \\
\hline Body mass index $\left(\mathrm{kg} / \mathrm{m}^{2}\right)$ & $28.9 \pm 0.3$ & $28.0 \pm 0.3$ & 0.06 & 0.10 \\
\hline Waist circumference $(\mathrm{cm})$ & $101 \pm 1.0$ & $97 \pm 0.9$ & 0.004 & 0.01 \\
\hline Hip circumference $(\mathrm{cm})$ & $104 \pm 1.0$ & $100 \pm 0.9$ & 0.002 & 0.005 \\
\hline Waist and hip ratio & $0.96 \pm 0.01$ & $0.90 \pm 0.02$ & 0.32 & 0.41 \\
\hline Systolic pressure $(\mathrm{mmHg})$ & $|3| \pm 2.0$ & $128 \pm 2.1$ & 0.25 & 0.37 \\
\hline Diastolic pressure $(\mathrm{mmHg})$ & $82 \pm 1.2$ & $78 \pm 1.3$ & 0.61 & 0.89 \\
\hline
\end{tabular}

Notes: Values are presented with means \pm SEM or \%. P: KPT2D versus T2D. $P$ adjusted: KPT2D versus T2D adjusted by age and sex.

Abbreviations: KPT2D, ketosis-prone type 2 diabetes; T2D, type 2 diabetes with ketosis.

Table 2 The Laboratory Results of the KPT2D and T2D Subjects

\begin{tabular}{|c|c|c|c|c|}
\hline & KPT2D & T2D & $\boldsymbol{P}$ & P Adjusted \\
\hline \multicolumn{5}{|l|}{ Glucose } \\
\hline Fasting glucose (mmol/L) & $13.3 \pm 0.2$ & $9.1 \pm 0.2$ & $<0.0001$ & $<0.0001$ \\
\hline Postprandial 2-h glucose (mmol/L) & $20.1 \pm 0.3$ & $13.9 \pm 0.3$ & $<0.000$ I & $<0.0001$ \\
\hline Hemoglobin Alc (\%) & $12.0 \pm 0.1$ & $9.8 \pm 0.1$ & $<0.0001$ & $<0.0001$ \\
\hline Fasting C-peptide (nmol/L) & $0.53(0.40-0.76)$ & $0.7 I(0.54-1.1)$ & $<0.000$ I & $<0.0001$ \\
\hline Postprandial 2-h C-peptide (nmol/L) & $0.79(0.56-1.24)$ & $1.80(1.18-2.41)$ & $<0.0001$ & $<0.0001$ \\
\hline$\Delta \mathrm{C}$-peptide (nmol/L) & $0.26(0.08-0.57)$ & $0.98(0.46-1.50)$ & $<0.0001$ & $<0.0001$ \\
\hline \multicolumn{5}{|l|}{ Lipids } \\
\hline Serum triglycerides (mmo/L) & $2.31(1.57-4.72)$ & $1.89(1.33-3.36)$ & $<0.0001$ & 0.0003 \\
\hline Serum total cholesterols $(\mathrm{mmo} / \mathrm{L})$ & $5.2 \pm 0.1$ & $4.9 \pm 0.1$ & 0.02 & 0.05 \\
\hline HDL-cholesterol (mmo/L) & $1.06 \pm 0.02$ & $1.13 \pm 0.02$ & 0.02 & 0.08 \\
\hline LDL-cholesterol (mmo/L) & $2.91 \pm 0.06$ & $2.71 \pm 0.05$ & 0.02 & 0.22 \\
\hline \multicolumn{5}{|l|}{ Liver enzymes } \\
\hline Alanine aminotransferase $(\mathrm{U} / \mathrm{L})$ & $63.1 \pm 3.8$ & $53.5 \pm 4.0$ & 0.08 & 0.44 \\
\hline Aspartate aminotransferase (U/L) & $43.5 \pm 2.8$ & $34.3 \pm 2.9$ & 0.02 & 0.15 \\
\hline \multicolumn{5}{|l|}{ Renal function } \\
\hline Serum creatinine $(\mu \mathrm{mol} / \mathrm{L})$ & $81.5 \pm 1.2$ & $79.8 \pm 1.2$ & 0.08 & 0.44 \\
\hline Serum uric acid $(\mu \mathrm{mol} / \mathrm{L})$ & $377 \pm 9$ & $360 \pm 9$ & 0.17 & 0.54 \\
\hline
\end{tabular}

Notes: Values are presented with means \pm SEM, \%. Serum TGs and C-peptides have been presented as median (interquartile range, IQR). P: KPT2D versus T2D. $P$ adjusted: KPT2D versus T2D adjusted by age and sex.

Abbreviations: KPT2D, ketosis-prone type 2 diabetes; T2D, type 2 diabetes with ketosis. 
Table 3 Pearson's Correlation Coefficients Between the Serum Triglycerides and a Variety of Parameters

\begin{tabular}{|l|l|l|l|l|}
\hline & $\gamma$ & $\begin{array}{l}\mathbf{9 5 \%} \\
\text { LCI }\end{array}$ & $\begin{array}{l}\mathbf{9 5 \%} \\
\mathbf{U C l}\end{array}$ & $\mathbf{P}$ \\
\hline Age & -0.04 & -0.18 & 0.09 & 0.53 \\
\hline Sex & 0.15 & 0.05 & 0.24 & 0.003 \\
\hline Body mass index & 0.20 & 0.09 & 0.29 & 0.0002 \\
\hline Hemoglobin Alc & 0.09 & -0.004 & 0.19 & 0.06 \\
\hline Serum total cholesterols & 0.53 & 0.45 & 0.59 & $<0.0001$ \\
\hline HDL cholesterols & -0.04 & -0.06 & 0.14 & 0.39 \\
\hline LDL cholesterols & 0.06 & -0.16 & 0.03 & 0.20 \\
\hline
\end{tabular}

Notes: $\gamma$ : Pearson correlation coefficient; $P$ : serum triglycerides versus variables. Abbreviations: LCL, lower confidence interval for difference; UCL, upper confidence interval for difference.

0.0001) and postprandial 2-h plasma glucose (2-h PG) $(P<=0.0001)$ when compared with the T2D group. The HbA1c levels in patients with KPT2D and T2D were 12.0 $\pm 0.1 \%$ and $9.8 \pm 0.1 \%$, respectively $(P<0.0001)$. Conversely, compared to the T2D group, the KPT2D group had lower levels of C-peptide $(P<0.0001)$ and 2-h C-peptide $(P<0.0001)$. The KPT2D group had higher levels of serum TGs compared to the T2D group, 2.31 (1.57-4.72) vs 1.89 (1.33-3.36) $\mathrm{mmol} / \mathrm{L}$, respectively, $P=0.0003$. The levels of serum total cholesterols (TCs) were borderline higher $(P=$ $0.05)$ in the KPT2D group than in the T2D group. The levels of HDL-cholesterol (HDL-C), and LDL-cholesterol (LDL-C) were not significantly different between the two groups $(P=$ NS) following adjustment by sex and age.

\section{Correlations of Serum TGs with Other Variables}

Table 3 reports the Pearson's correlation coefficients between the serum TGs and a variety of parameters, including age, sex, BMI, HbAlc, serum TCs, HDL-C, and LDL-C. Among which, sex $(\gamma=0.15, P=0.003)$, BMI $(\gamma=0.20, P=0.0002)$, and serum TCs levels $(\gamma=$ $0.53, P<0.0001)$ correlated positively with serum TGs; whereas, age, HbA1c, HDL-C, and LDL-C were not significantly correlated with serum TGs. Taking into consideration of all the significantly correlated variables (sex, BMI, and serum TCs), we performed multivariate regression analyses. The differences in serum TGs between the two groups remained significant $(P=0.01)$ after adjustment.

\section{Stratified Analysis of Serum TGs Level}

Based on the National Cholesterol Education Program Adult Treatment Panel III criteria ${ }^{10}$ for serum TGs levels, we investigated the distribution of serum TGs in the two groups shown in Figure 1. The prevalence of patients with normal serum TGs levels was lower $(P=0.019)$ in the KPT2D group $(30.2 \%)$ than in the T2D group $(41.3 \%)$. Meanwhile, the prevalence of patients with very high levels of serum TGs was 6-fold higher $(P<0.0001)$ in the KPT2D group (22.2\%) than in the T2D group $(3.6 \%)$. Twenty-one subjects in the KPT2D group (9.9\%) compared to none in the T2D group had serum TGs levels $\geq$ $11.2 \mathrm{mmol} / \mathrm{L}$. Furthermore, six subjects (2.8\%) in the KPT2D group compared with only one subject $(0.5 \%)$ in T2D group experienced hypertriglyceridemia-induced acute pancreatitis (clinical assessment) (Figure 2).

\section{The Correlation of Blood Glucose and C-Peptide with Serum TGs}

Figure 3 shows blood glucose and C-peptide concentrations for different levels of serum TGs levels in all enrolled subjects. Compared with individuals in the normal group, fasting glucose concentrations were significantly higher in the high $(P=0.003)$ and very high $(P<$ 0.0001) TGs groups. Both the postprandial 2-h glucose concentrations $(P<0.0001)$ and the HbA1c levels $(P=$ 0.0008 ) were higher in the very high TGs group than in the normal TGs group. The fasting C-peptide levels were higher in all the hypertriglyceridemia groups than in the normal group. The postprandial 2-h C-peptide levels were higher $(P=0.03)$ in the borderline-high TG group, although no significant difference was observed between the high and very high TGs groups. The $\Delta \mathrm{C}$-peptide (2-h C-peptide level minus fasting C-peptide level) was lowest in the very high TGs group $(P=0.04)$, demonstrating a significant depression of $\beta$-cell functions in individuals of this group.

\section{Discussion}

In this study, we compared the characteristics of 409 young individuals at the onset of KPT2D and T2D. Consistent with previous studies, KPT2D was predominant in male individuals and the prevalence was seven times higher in men compared to women. ${ }^{3,11}$ Though the significance of this sex-based difference is unknown, the underlying causes could be related to body fat distribution, hormonal factors, and changes in insulin sensitivity. ${ }^{3,11} \mathrm{We}$ 


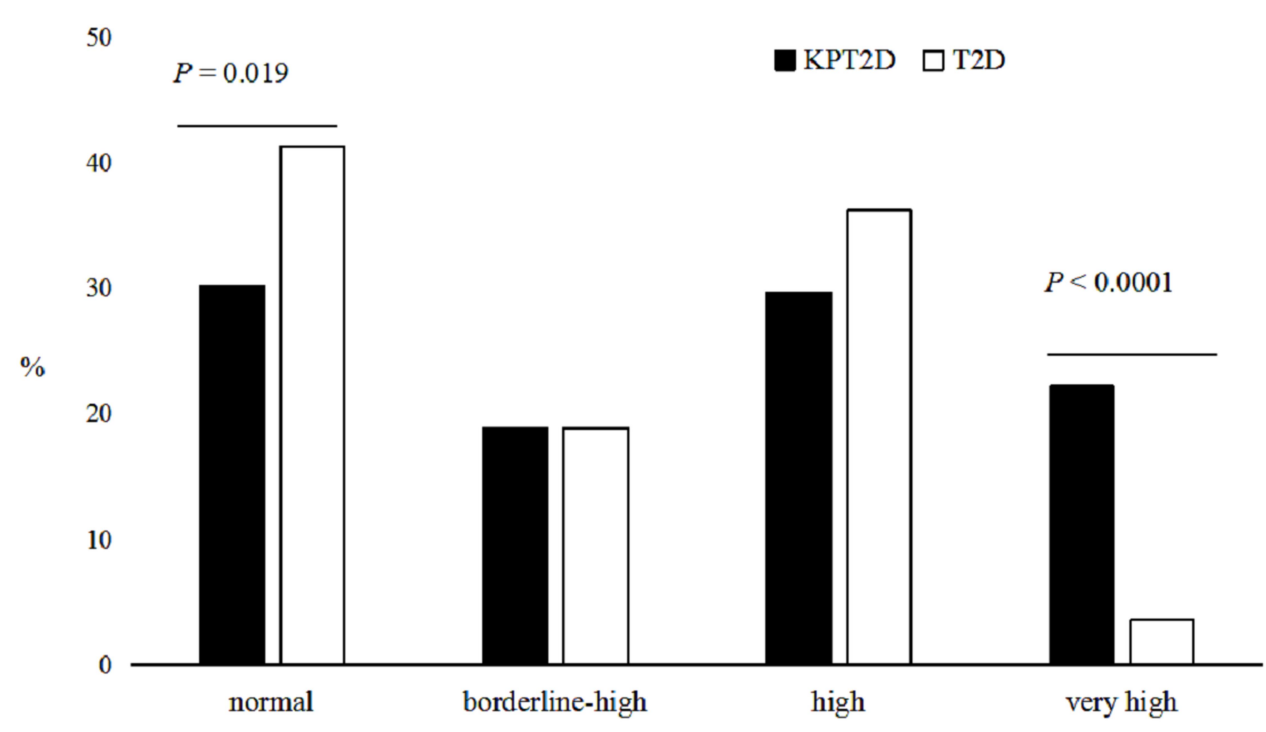

Figure I The distribution of serum triglyceride levels in the two groups.

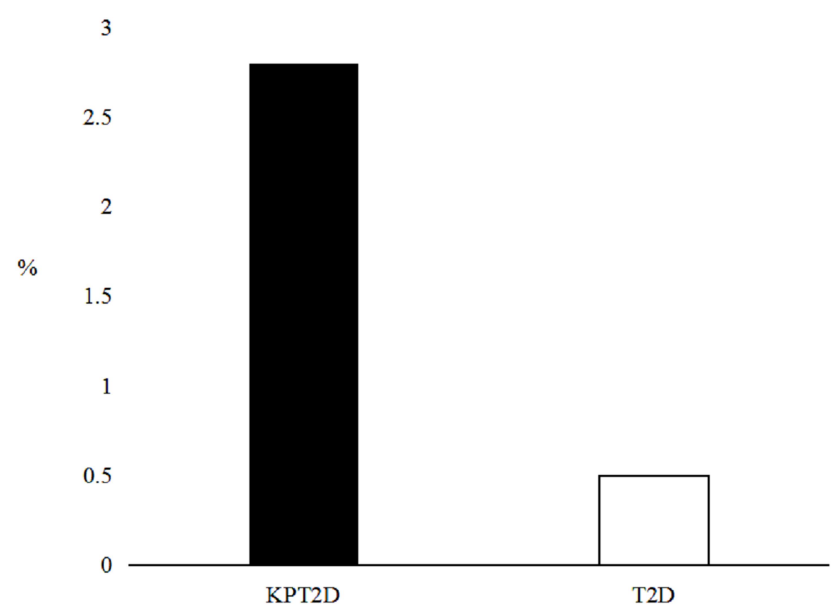

Figure 2 The prevalence of hypertriglyceridemia-induced acute pancreatitis in the two groups.

also found that the onset age for KPT2D was lower than that for T2D. Additionally, KPT2D has also been increasingly reported in the pediatric population. ${ }^{6,12}$

Variables related to elevated glucose levels such as $\mathrm{HbAlc}$, FPG, and 2-h PG were significantly higher in patients with KPT2D than in those with classical T2D. Meanwhile, fasting and 2-h C-peptide concentrations, as well as the $\Delta \mathrm{C}$-peptide, were lower in the KPT2D group, indicating that basic and postprandial insulin secretion were more depressed in this group compared to the T2D group. These results were consistent with previous reports, ${ }^{2}$ and a possible explanation could be that $\beta$-cell functions are more severely impaired in patients with KPT2D at the onset of the disease because of more severe glucotoxicity. $2,8,13$
As for the effects of lipotoxicity on KPT2D, previous findings have been inconsistent. In vitro studies have shown that prolonged exposure of rat $^{14}$ and human ${ }^{15}$ islets to free fatty acids leads to a decrease in glucose-stimulated insulin secretion. However, findings from human studies have been contradictory. ${ }^{16-18}$ Umpierreza et al ${ }^{18}$ have reported that intralipid infusion for 48 hours in patients with KPT2D was not associated with $\beta$-cell decompensation. Zhang et $\mathrm{al}^{3}$ and Lontchi-Yimagou et $\mathrm{al}^{8}$ have also suggested higher serum TGs in ketosis-prone diabetes. However, most of their study samples were relatively small and without controlled variables, furthermore, the distribution of serum TGs was not determined. In order to better understand the role of serum TGs in KPT2D, we studied serum TGs by comparing KPT2D with T2D individuals. The serum TGs were significantly higher in the KPT2D individuals as revealed by multivariate regression analyses. Furthermore, by stratified analyses, we determined that differences in serum TGs were mainly in decreased prevalence of normal (TGs $<1.7 \mathrm{mmol} / \mathrm{L}$ ) and elevated prevalence of very high (TGs $\geq 5.6 \mathrm{mmol} / \mathrm{L}$ ) groups in KPT2D than T2D individuals, respectively. We found that very high serum TGs levels were 6-fold higher in KPT2D than T2D individuals, and nearly one-tenth of KPT2D individuals had serum TGs levels $\geq 11.2 \mathrm{mmol} / \mathrm{L}$, which meant that KPT2D individuals were more likely to have severe hypertriglyceridemia. Accordingly, the occurrence of hypertriglyceridemia-induced acute pancreatitis was significantly higher in KPT2D than T2D individuals. Individuals in the very high TGs group also had the highest glucose concentrations and markedly impaired $\beta$ cell functions. Thereby, the results indicated that glucotoxicity, 

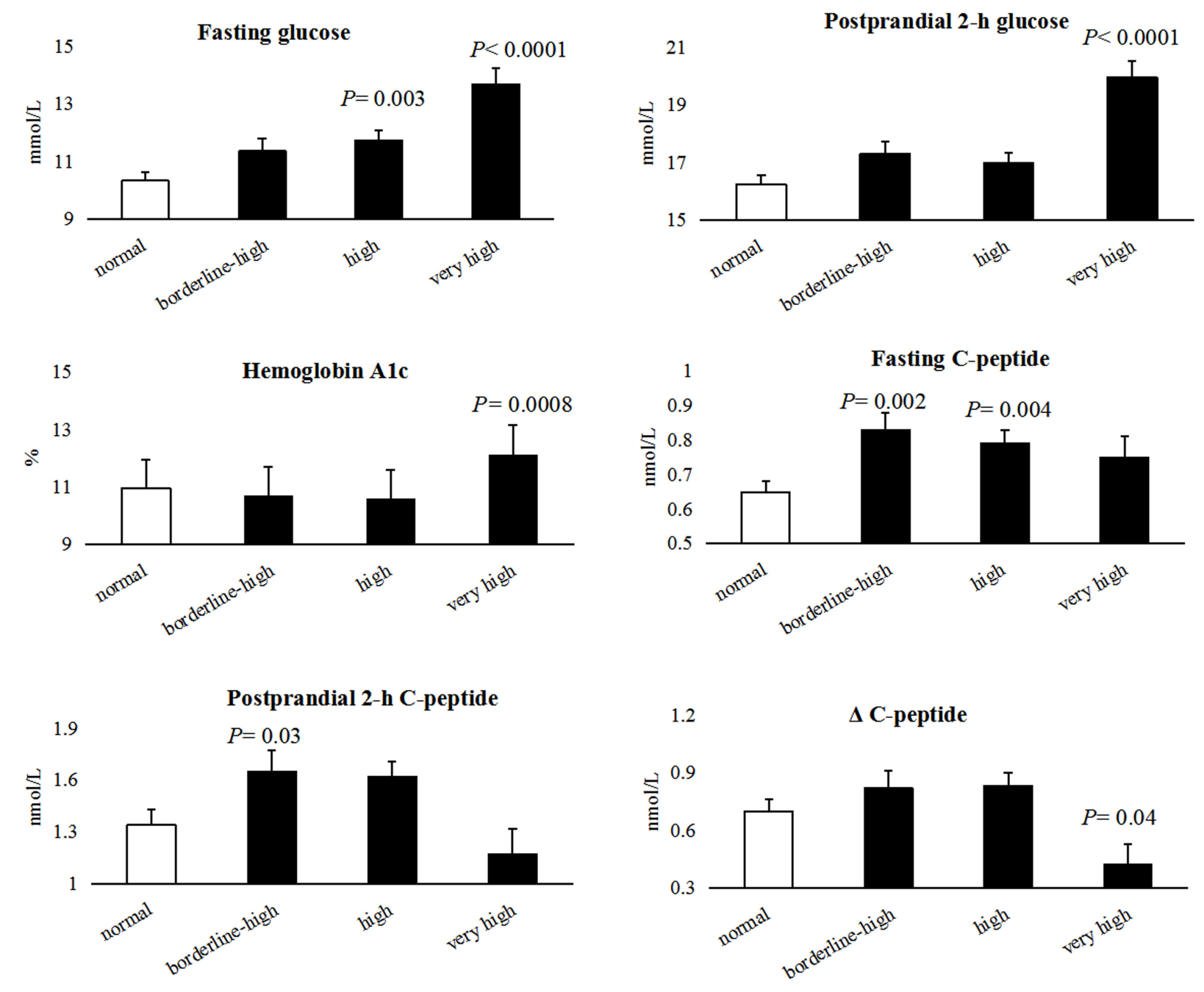

Figure 3 The plasma glucose and C-peptide concentrations in different levels of serum triglycerides in all enrolled subjects.

together with lipotoxicity might cause insulin receptor insensitivity and impairment of $\beta$-cell functions that ultimately induced the dysfunction of insulin secretion, leading to ketogenesis. However, the underlying mechanisms are not yet understood. One explanation is that excess TG in the bloodstream leads to the compromised capacity of systemic tissues to metabolize glucose (insulin receptor insensitivity). Another potential explanation is that lipotoxicity may inhibit insulin gene expression ${ }^{13}$ partly via negative regulation of the transcription factor pancreatic duodenum homeobox- $1^{19}$ or by reducing the efficiency of proinsulin to insulin conversion within $\beta$-cells. ${ }^{20,21}$

Our results support the idea that serum TGs play an important role in the onset of youth KPT2D. Very high levels of serum TGs have been reported to associate with increased pancreatitis $^{22}$ and cardiovascular risks ${ }^{23}$ and our findings revealed a substantially higher pancreatitis prevalence in KPT2D than in classical T2D subjects. Further studies are necessary to investigate the long-term cardiovascular risks in these young patients. In addition, mechanistic studies are required to determine whether the resulting hypertriglyceridemia was due to increased TGs production, reduced TGs catabolism, or both. We believe that lifestyle changes as well as lipid-lowering drugs may be beneficial in reducing the incidence of ketosis as well as in stabilizing the progression of the disease.

The present study has some limitations that should be considered. First, as we focused on new-onset diabetes in adolescents or young adults, our findings might not be applicable to other age groups or to those with long-standing diabetic disease. Second, as an academic tertiary hospital, we enrolled patients with relatively severe hyperglycemia. The average 
HbA1c in patients with T2D and KPT2D was $9.8 \%$ and $12.0 \%$, respectively. Our conclusions, therefore, cannot be extrapolated to outpatients with modest hyperglycemia. Finally, this was a single center study with a relatively small number of inpatients. Multi-center studies with larger sample sizes should be performed in the future to further clarify the characteristics of individuals with KPT2D.

In summary, we compared the clinical characteristics of young patients with KPT2D and classical T2D. KPT2D is a subtype of T2D characterized by the traits of overweight or obesity, but presents more severe hyperglycemia and impaired $\beta$-cell functions. In addition, we showed that elevated serum TGs, and especially very high TG levels, are also significantly associated with KPT2D in young individuals which were seldom considered in previous studies. Both glucotoxicity and lipotoxicity might eventually lead to the $\beta$-cell decompensation at the onset of KPT2D.

\section{Acknowledgments}

The study was supported by the National Natural Science Foundation of China (No. 81600702); the research grant for the Cooperation between Medicine and Engineering of Shanghai Jiao Tong University (No. YG2015QN43); the research grant of the Shanghai Municipal Commission of Health and Family Planning (No. 20144Y0140); the research grant for Medical Science and Technology of Zhejiang Province of China, (No. 2014KYA234), and the Foundation of Hangzhou Medical College (No. 2015XZB01).

\section{Disclosure}

None of the authors declare any potential conflicts of interest associated with this study.

\section{References}

1. Winter WE, Maclaren NK, Riley WJ, Clarke DW, Kappy MS, Spillar RP. Maturity-onset diabetes of youth in black Americans. $N$ Engl $J$ Med. 1987;316(6):285-291. doi:10.1056/NEJM198702053160601

2. Mauvais-Jarvis F, Sobngwi E, Porcher R, et al. Ketosis-prone type 2 diabetes in patients of Sub-Saharan African Origin: clinical pathophysiology and natural history of $\beta$-cell dysfunction and insulin resistance. Diabetes. 2004;53(3):645-653. doi:10.2337/diabetes.53.3.645

3. Zhang M, Li Y, Cui W, et al. The clinical and metabolic characteristics of young-onset ketosis-prone type 2 diabetes in China. Endocr Pract. 2015;21(12):1364-1371. doi:10.4158/EP15778.OR

4. Nagasaka S, Ishikawa S, Itabashi N, et al. Ketoacidosis-onset type 2 diabetes in Japanese: association with the widespread distribution of soft drinks and vending machines (multiple letters). Diabetes Care. 1998;21(8):1376-1377. doi:10.2337/diacare.21.8.1376

5. Du S, Zhang H, Wu H, Ye S, Li W, Su Q. Prevalence and gender differences of metabolic syndrome in young ketosis-prone type 2 diabetic individuals: a retrospective study. Diabetes Metab Syndr Obes. 2020; Volume 13:2719-2727. doi:10.2147/DMSO.S252492
6. Tan H, Zhou Y, Yu Y. Characteristics of diabetic ketoacidosis in Chinese adults and adolescents - A teaching hospital-based analysis. Diabetes Res Clin Pract. 2012;97(2):306-312. doi:10.1016/j.diabres.2012.05.004

7. Das GR, Ramachandran R, Gangadhara P, et al. Clinical characteristics, beta-cell dysfunction and treatment outcomes in patients with A $-\beta+$ Ketosis-Prone Diabetes (KPD): the first identified cohort amongst Asian Indians. J Diabetes Complications. 2017.

8. Lontchi-Yimagou E, Nguewa JL, Assah F, et al. Ketosis-prone atypical diabetes in Cameroonian people with hyperglycaemic crisis: frequency, clinical and metabolic phenotypes. Diabet Med. 2017;34 (3):426-431. doi:10.1111/dme.13264

9. American Diabetes Association. Diagnosis and classification of diabetes mellitus. Diabetes Care. 2006.

10. Grundy SM. Third report of the National Cholesterol Education Program (NCEP) Expert panel on detection, evaluation, and treatment of high blood cholesterol in adults (Adult treatment panel III) final report. Circulation. 2002.

11. Wang X, Tan H. Male predominance in ketosis-prone diabetes mellitus. Biomed Rep. 2015;3(4):439-442. doi:10.3892/br.2015.461

12. Matsui J, Tamasawa N, Tanabe J, et al. Clinical characteristics of Japanese youth-onset type 2 diabetes with ketonuria. Diabetes Res Clin Pract. 2005;70(3):235-238. doi:10.1016/j.diabres.2005.03.037

13. Kitabchi AE, Umpierrez GE, Miles JM, Fisher JN. Hyperglycemic crises in adult patients with diabetes. Diabetes Care. 2009;32 (7):1335-1343. doi:10.2337/dc09-9032

14. Zhou YP, Grill VE. Long-term exposure of rat pancreatic islets to fatty acids inhibits glucose-induced insulin secretion and biosynthesis through a glucose fatty acid cycle. J Clin Invest. 1994;93(2):870-876. doi:10.1172/JCI117042

15. Jacqueminet $S$, Briaud I, Rouault $C$, Reach G, Poitout V. Inhibition of insulin gene expression by long-term exposure of pancreatic $\beta$ cells to palmitate is dependent on the presence of a stimulatory glucose concentration. Metabolism. 2000;49(4):532-536. doi:10.1016/ S0026-0495(00)80021-9

16. Boden G. Effects of free fatty acids (FFA) on glucose metabolism: significance for insulin resistance and type 2 diabetes. Exp Clin Endocrinol Diabetes. 2003;111(03):121-124. doi:10.1055/s-2003-39781

17. Komatsu M, Takei M, Ishii H, Sato Y. Glucose-stimulated insulin secretion: a newer perspective. J Diabetes Investig. 2013;4 (6):511-516. doi:10.1111/jdi.12094

18. Umpierrez GE, Smiley D, Robalino G, Peng L, Gosmanov AR, Kitabchi AE. Lack of lipotoxicity effect on $\beta$-cell dysfunction in ketosis-prone type 2 diabetes. Diabetes Care. 2010;33(3):626-631. doi:10.2337/dc09-1369

19. McKinnon CM, Docherty K. Pancreatic duodenal homeobox-1, PDX-1, a major regulator of beta cell identity and function. Diabetologia. 2001;44(10):1203-1214. doi:10.1007/s001250100628

20. Weigert C, Brodbeck K, Staiger H, et al. Palmitate, but not unsaturated fatty acids, induces the expression of interleukin- 6 in human myotubes through proteasome-dependent activation of nuclear factor- $\mathrm{\kappa B} . J$ Biol Chem. 2004;279(23):23942-23952. doi:10.1074/jbc.M312692200

21. Weigert C, Klopfer K, Kausch C, et al. Palmitate-induced activation of the hexosamine pathway in human myotubes - Increased expression of glutamine: fructose-6-phosphate aminotransferase. Diabetes. 2003;52(3):650-656. doi:10.2337/diabetes.52.3.650

22. Christian JB, Arondekar B, Buysman EK, Jacobson TA, Snipes RG, Horwitz RI. Determining triglyceride reductions needed for clinical impact in severe hypertriglyceridemia. Am J Med. 2014;127(1):3644.e1. doi:10.1016/j.amjmed.2013.09.018

23. Berglund L, Brunzell JD, Goldberg AC, et al. Evaluation and treatment of hypertriglyceridemia: an endocrine society clinical practice guideline. J Clin Endocrinol Metab. 2012;97(9):2969-2989. doi:10.1210/jc.2011-3213 


\section{Publish your work in this journal}

Diabetes, Metabolic Syndrome and Obesity: Targets and Therapy is an international, peer-reviewed open-access journal committed to the rapid publication of the latest laboratory and clinical findings in the fields of diabetes, metabolic syndrome and obesity research. Original research, review, case reports, hypothesis formation, expert opinion and commentaries are all considered for publication. The manuscript management system is completely online and includes a very quick and fair peer-review system, which is all easy to use. Visit http://www.dovepress.com/testimonials.php to read real quotes from published authors.

Submit your manuscript here: https:/www.dovepress.com/diabetes-metabolic-syndrome-and-obesity-targets-and-therapy-journal 